\title{
Better Chinese Cuisine for the Belt and Road People's Connectivity: A Zhejiang Story
}

\author{
Shiming Tang, Jingmin Zhang*, Changjuan Guo, Wenjie Ge \\ Hangzhou Normal University \\ Hangzhou, Zhejiang, China \\ *Eamil: 2013409046@qq.com
}

\begin{abstract}
Chinese food is the manifestation of Chinese traditional culture, and recognized by the world gradually. The popularity of Chinese food shows the unique charm of Chinese traditional culture. But there are still many problems to be solved in the process of Chinese food going to the world. Therefore, this paper puts forward the following views: (1) Promoting and highlighting food culture actively; (2) Improving overseas Chinese food developing research and ensuring quality; (3) Integrating excellent resources and achieving win-win cooperation; (4) Connecting with international mainstream and promoting cultural exchange. In addition, Zhejiang Federation of overseas Chinese organized the "Ten thousand overseas Chinese restaurants to tell the good Story of China", to help overseas Chinese restaurants operating Chinese cuisine, spreading Chinese culture, getting on the Internet express, building "overseas public meeting room" and telling the Chinese stories. By strengthening top-level design, concentrating superior resources, enhancing cooking skills by standardization, integration and internationalization, developing special food, being goodwill messenger, and telling" good stories" of China, path exploration and work innovation of "One Belt And One Road" is achieved finally.
\end{abstract}

\section{Keywords: Chinese Cuisine; People's Connectivity;} Zhejiang Story

\section{RESEARCH BACKGROUND}

"Zuo Zongtang Chicken" and "Panda Fast Food" popular in North America; overseas Chinese food took the lead in winning popular trust among ordinary people in developed countries and taking the top spot in the festival. Win fast food chain. Chinese food will be a Chineseforeign civil diplomacy and even "Belt and Road" popular common important platform.

The Chinese cuisine is an annotation of traditional Chinese culture, and is the inheritance and crystallization of several thousand years of cultural accumulation and ancient wisdom.

With the promotion and improvement of Chinese food, its impact on the global scale is increasing. The popularity of "Zuo Zongtang Chicken " on the North American dining table, as well as the stunning development speed of panda fast food, shows that Chinese food and exotic culture can be fully mixed and mutually beneficial .

It is not only the meal of the Chinese food, but also the long - distance and mellow Chinese food and the humanities. The Chinese food has promoted the Chinese humanity and formed a virtuous circle. In the great background of the "Belt and Road" efforts, this virtuous circle opens up an important path for the communication of the people. It is worth exploring and studying.

In Chinese culture, unique flavor, low price by Europe and other countries like the United States in 2014, according to "times weekly survey, Chinese food in the shopping list of Americans during the Christmas season ranked second after the United States movie tickets. Fortune magazine $2014<>" 100$ things "Americans are most proud of the Chinese takeout, among them. Zuo Zongtang chicken, Pan-Fried Meat Dumplings, Spring rolls, fried rice is popular. In the current number of restaurants in the United States is 5 6 million, more than the sum of McDonald's, Wendy's and Burger King fastfood chains.

Under the background of Chinese food has attracted worldwide attention in recent years, China brands catering enterprises launched the "going out" strategy, including a five delicacy, sea fishing, Meizhou Dongpo, flower garden, Wong Kee Huang, Quanjude, dozens of small food enterprises. Now the Chinese are no longer Kung Pao Chicken egg roll, and drink small colored umbrella, Chinese food has become the mainstream of society developed areas of cultural activities.

\section{II.HISTORICAL REVIEW}

Thousands of miles journey "looking for Zuo Zongtang" preaching the Chinese folk diplomacy Jinshan contribution, origin, identification and Chinese immigrants in deeds. Do a dish, every year to create billions of dollars in profits, said Chinese success of "going out" and "flying into the homes of ordinary people" good stories.

Big data show that Zuo Zongtang chicken is the most popular food in North America Chinese. According to a 2014 survey, the more than 800 City, more than 30 thousand Chinese restaurants have this dish. To be honest, just taste and appearance, this famous dish plain, was so popular, more is due to its name. Who is Zuo Zongtang why? A general invented a dish? Stimulate the exploration of this dish curious people united these two problems, produced a lot of research monographs, broadcast reports, documentary.

In 2004, a good - looking man came into contact with the dish in the U.S. Chinese restaurant to find a history of its invention. So, in the United States looking for a Chinese restaurant in China, an interview was looking for a Chinese restaurant, an interview with an image of characters, from an old restaurant to a historian to a descendant of Zuo Zongtang.

In fact, the documentary review since the gold rush, 
Chinese immigrants in the United States will bring Chinese since more than a century of vicissitudes of history. The gold rush, the Chinese Exclusion Act, the Sino Japanese War, civil war, Sino US relations and so on big events gathered in a chicken dish, show the Sino US political relations, immigrant identity, relationship between cultural change and Chinese food.

Looking for Zuo Zongtang is a historical and cultural journey, but also on the chicken Zuo Zongtang propaganda conversely, a long history of the Chinese China introduced to the world, a fast food to Chinese cultural symbol is extended to the United States. This is the Chinese people to promote the high streets and back lanes with stories, both sides, like a coin complement each other, it interacts. Both national, but also the world. These research reports, the story spread, Zuo Zongtang established the reputation of chicken in the United States for the customer in mind.

The true mingled with the false story, genuine and fake characters, the history of Oriental flavor, undoubtedly give this dish a lot of charm. Chinese need more general Zuo Zongtang name, form the brand effect, the long broad Chinese all over the world. To do a dish, every year to create billions of dollars in profits, Chinese modern historical and cultural story ordinary Americans penetrated into the heart.

\section{SHORT PLATE ANALYSIS:}

Delicious cheap benefit is not high, not individual business scale, environmental health management is not strict, vicious competition. Chinese catering brand image is not good, very few Chinese dishes sell high; the hearts of the people, the formation of reputation is quite limited.

Chinese restaurants are widely distributed overseas, and international people like Chinese food are numerous, and their development momentum and potential are staggering. But so many Chinese restaurants can differentiate themselves and form brands. They can go deep into the hearts of overseas people and form word - of - mouth effects.

So far, the world image of Chinese food is mainly delicious and cheap, which leads to low cost. Why are we close to Japan's sushi and Korean barbecue can sell high price? Why is it so profound that the Chinese food is difficult to harvest brand benefit?

There are many bottlenecks in the overseas Chinese food industry. Take the United States as an example, Chinese food business lasts more than 100 years and the employees exceed 300,000 , but more than $75 \%$ of them are still self-employed, most of which are cheap fast food and takeout shops.

The Chinese food industry dominated by family shop, has not formed the brand, led to a limited scale. At the same time, the food environment is an important aspect of food culture in the aesthetic process, good dining environment can enhance the diet taste. How to achieve the beauty of artistic conception, how to choose the suitable layout and dining environment, how to restaurant the four layout of green plants, how to set up a restaurant lighting different, this is must study modern catering business problems. In contrast, the small scale facilities often relatively simple, health management is relatively weak.

Modern people continue to get food health promotion in the information era is the source of the source, hope to see their own health information, and the reality of catering to each other, the preferred good dishes. Most Chinese are fake (in some European amateur for the city, the Vietnamese opened restaurants than Chinese and more.) a cheap peer vicious competition, it is difficult to integrate into the mainstream of excellence banquet, caused by the poor image.

The first wave of Chinese overseas shop can be traced back to the 160 to 190 years ago, and the second wave is at the beginning of the reform, including Quanjude, a number of well-known state-owned enterprises to go out, but because of the lack of understanding of the local investment location are not careful, mismanagement and other reasons now almost The whole army was wiped out.. Catering enterprises to explore overseas market more cautious, at this stage, food and beverage brands to enter the overseas just in exploration mode, not likely to get a very high return on revenue. The content of backward technology, shortage of talents, the competition deteriorated, meager profits and other practical problems become the main problems restricting the development of overseas Chinese.

\section{DIFFICULT PROBLEM SOLVING}

Correspondence analysis of the short board, put forward the active promotion, highlighting the delicacy culture; improve the overseas research and development, quality guarantee standard; integration of special highquality new, collaborative win-win cooperation; integrate the international mainstream, please come in and go out four countermeasures and suggestions.

\section{A. Delicacy, Delicacy and Culture.}

Adhere to the delicacy culture. Nowadays, from the layout of the restaurant, the decoration to the food color, fragrance, taste, shape, with no culture. In the catering innovation process, should always be to enhance cultural characteristics as the main direction of operation, to create a good, healthy and the melody of culture.

From ancient to present, with the development of the times, people' $s$ aesthetic interest and demand have changed greatly, and the food and beverage management innovation cannot be held in a certain form .

As long as there is a unique style, healthy and civilized, will produce good results and benefits. As long as the culture is firmly infiltrated in all aspects of catering, or catering management has always around the main theme of culture. It will be popular, attract consumers.

To create a unique food culture. Chinese food should be good at playing cultural cards, in order to cultivate and strengthen their own customer base with soft power. First of all, deliberately maintain their own Chinese food. The panda brand is a national fast food, not an American fast food, which distinguishes it from American fast food such as McDonald's and avoids direct competition with these giants. 
For example, China has 24 solar terms, has a unique festival, panda fast food always in specific solar terms and festivals to launch specific activities, will also introduce some Chinese cultural common sense in the store, such as feng shui, Chinese characters. History stories and so on. In the restaurant, often play Xie Chinese folk music as background music and so on. All these make Chinese customers feel friendly, non-Chinese customers feel new and knowledgeable, have a sense of acquisition, can be said to kill two birds with one stone.

\section{B. Standardization-ensuring Quality and Characteristics}

Make cooking standard. Standardization and cooking experience are not only opposite, but also interchangeable and interdependent. There is also art in standard things, such as air catering, food packaging, propaganda and so on

Chinese food can improve the efficiency and profitability of catering enterprises by means of standardization. However, the standardization of Chinese food is not necessarily limited to the cooking process standards of Chinese food, catering enterprises can be based on the characteristics of the enterprise itself. In the cooking process of Chinese food, the management of Chinese food enterprises, the operation practice of staff and so on, the standardization work is carried out step by step.

Highlight the food nutritional value. A dish goods if only is tasty and healthy for you, there will be no vitality. When we are in the design of innovative dishes, should make full use of the principles of nutrition, innovation, healthy dishes to attract customers. Modern Chinese customers not only in the pursuit of taste, appearance and so on, and put more attention on the nutrition of the dishes, but also become the fashion.

In the development of innovative dishes should pay attention to food and nutrition, in-depth understanding of the nutritional value of the raw materials, and according to different raw materials, different collocation effect arising from the combination of the useful attempt, in the choice of materials and cooking should give full consideration to the nutritional factors, better play the nutritional value of food.

\section{Integration to Achieve synergy and Win-win}

Integration of Chinese and Western cooking technology. Different places of cuisine have different cooking technology. Overseas Chinese food industry, can not be satisfied in a cooking in a "one draft fresh." And to absorb and learn from some practices of other cuisine, especially Western food, the traditional cooking methods for the present, Western-style cuisine technology as a Chinese. With the increase of cultural exchanges between China and foreign countries, the introduction of Western cuisine cooking methods. It is also desirable to develop new dishes that combine Chinese and western.

As an example of Sichuan cuisine, which is quite complete in cooking process, the development of Sichuan cuisine is also to draw lessons from or improve the specialty of other dishes. Many Sichuan cuisine chefs also begin to learn Cantonese cuisine, Huaiyang cuisine, Jin Cai' $s$ face food and the like, as well as the hanging soup of Shandong cuisine. The Sichuan cuisine " dry pot with skin beef ", which is introduced by Shu State, has been used for reference to the cooking process of the dish, so that the dish can greatly improve the quality of the beef, so that the dish is well received by consumers with the characteristics of shape and shape .

Integration to create innovative brand. Innovation is the eternal theme of dishes catering industry, but also the pursuit of the goal and diligently cooking workers enjoy the momentum of development. In the process of product innovation, should follow the international food diet "five light" trend, to the development of light oil, light sugar, light salt, light fat, light seasoning. It pays attention to diet the environment, more standardized service personnel clothing, etiquette and cooperation.

In the catering business, the new model can explore. All flowers bloom together. Direct chain operation, establish a corporate brand image; franchising, unified technical quality, profit sharing; group management, through the integration of assets, strategic integration, cooperation and mergers and acquisitions across the enterprise, and enhance competitiveness. From the operating characteristics in innovation. Also pioneers, catering to the management style is more diversified, the prosperity and development of the catering industry to make more contributions.

\section{Internationalization-meeting the Needs of the Masses}

Comply with the international trend. The food and beverage industry as an important part of the third industry, with its large market, fast growth has attracted wide attention, but also developed a foreign carrier of capital and brand output. The innovation of food products, will not only be in vegetables, vegetables, recipes, environment, service activities, etc. hand, continue to lead the trend. The design and development of catering enterprises to adapt to market demand, to maintain the fundamental competitiveness, but also the image of an enterprise, the technical level, the specific performance and development efforts.

In the fierce competition in the catering industry, the innovation of the dishes has become an important part of participating in the market competition. Modern customers often prefer to choose new dishes, have their own potential and develop new dishes to meet the needs of consumers.

Advocating multiple sustainable development. To accurately analyze the present situation, predict the future and seize the first chance, we must grasp the consumer's value concept in a developmental way. The concept of consumption. Creatively guide the consumption of Chinese food. If the combination of Chinese and Western food will gradually become a trend, the diversity of food style will inevitably bring changes in taste. Therefore, the culinary workers should emphasize keeping pace with the times when developing innovative dishes. Only by continuously introducing generations of dishes that more and more want to eat, can Chinese food have a sustained vitality. Therefore, the whole process from selection of materials, ingredients to cooking. Stress after-meal satisfaction. 
At the same time, innovative dishes of raw materials should not blindly pursue precious, high-grade, cooking technology should not be too complicated. Pursuit of complex, new Chinese dishes, to stick close to popular demand. Delicacy delicacies, only accepted by the majority of consumers, it has great vitality. The promotion of innovation should be based on the dishes. The easy and cheap raw materials.

\section{V.THE ROLE OF THE CHINESE FEDERATION OF OVERSEAS CHINESE}

In the promotion of Belt and Road Initiative under the Zhejiang Federation organized the implementation of the "overseas Chinese restaurant - with Chinese speak good story". To help overseas Chinese business Chinese delicacy, spread the good Chinese culture, an Internet plus Express; build a good overseas public reception hall "," Chinese told the story people connected.

In 2016, Zhejiang Federation Chairman Wu Jing and other leaders to seize the opportunity of the G20 summit in Hangzhou, organized the implementation of the "overseas Chinese restaurant - with Chinese speak good story", "please come in" and "going out" education market, build the "overseas public reception hall".

Now the event has collected restaurant information, overseas entry million in the United States, Belgium, Czech, Brazil, a city of 37 restaurants in Spain and other 23 countries overseas in the configuration of nearly 2000 high-definition smart TV screen, and gradually build up a set of network ordering, cultural promotion, social networking platform has also developed the "global Chibian." App, to facilitate national diners appreciation.

In 2017, in order to further enhance the cooking skills of overseas Chinese restaurants, revitalize the overseas Chinese food industry, promote the Chinese food culture. The Zhejiang Federation of overseas Chinese invited overseas Chinese restaurant owners and chefs to return home. Known as "Zhejiang Whampoa" known as Zhejiang Institute of Commerce and Technology, and other schools held a number of overseas Chinese cuisine cooking skills training courses, so that overseas Chinese restaurant owners meet in Hangzhou, return to further study, understand the culture of Zhejiang cuisine. Preach a good story about Zhejiang.

At the same time, Zhejiang Institute of hand 12 national universities, hundreds of industry masters, to create "teaching resources" cooking resources covering the country. Chinese eight, standard, induction and consolidation China cooking intangible heritage craft, culture. The library currently has more than 10 thousand dishes, 4680 process video, 5000 cultural allusions 25000 , resources, 24500 students. Information resource library will provide technical support and innovation for overseas Chinese, free for students to use.

Hunger breeds discontentment, food and beverage contains rich cultural meaning and precipitation. Sixty million of the $90 \%$ overseas Chinese engaged in catering, won the overseas universal love.

Continuous Zhejiang food training to help overseas Chinese food operators to become a good Chinese food master and the Chinese culture of the spread of messengers, on the Internet Express, to assume the responsibility and obligations of good exchanges between China and foreign countries. It promotes the relationship between China and the host countries.

As the "Zhejiang Federation of overseas Chinese restaurant - with China speak good story" based on, so that people around the world to know the "Live Flesh" Chinese, creating a "overseas public reception hall", "speak well of the Belt and Road" "please come in" and "going out" of the "popular phase" story.

\section{FUTURE PROSPECT}

Strengthen the top - level design , centralized dominant resources, Chinese food, standardization, integration and internationalization will be close to the overseas demand, improve the cooking skills, develop catering adaptation, make good friends and good messenger, tell the " good story " of China, create the " good living room " in China, and realize the " people - centered communication " .

In recent years, large Chinese enterprises of its own financial strength, management talent, entrepreneurial ability have been greatly improved, which many Chinese turnover million per store. With the increase of China economic strength, and expand the international influence, enhance the ability to accept overseas China food culture, Chinese food acceptance is also on the rise. Chinese "going out", "service The Belt and Road" people connected will accomplish much.

As the Vice - Chairman of the Chinese Federation of Overseas Chinese, the Vice - President of the Zhejiang Provincial Political Consultative Conference (CPPCC) and the Chairman of Zhejiang Overseas Chinese Federation, Ms. Wu Jing, have adopted the Chinese cuisine , promoted the cooking skills, played the unique advantages of Chinese and foreign countries , played a good role in promoting the peaceful friendship and cultural exchange between China and the country, and played a positive role in the realization of China 's dream . Force", "be a good folk friendship emissary again dedication "and so on lofty goal."

\section{ACKNOWLEDEG}

This paper was a particial achievement and financially supported by the All-China Federation of Returned Overseas Chinese Project (17DZQK203)“Zhejiang Stories on the Belt and Road People's Connectivity" and the 4th Academic Conference Project for Zhejiang Provincial Federation of Social Sciences (Sub-forum 201830) "Zhejiang Hub Construction for the Belt and Road".

\section{REFERENCE}

[1] "Belt and Road Initiative" China staff cultural fusion and path exploration ", Tang Shiming,

[2] Hangzhou Normal University, 2015 year project, bear the title, won the first prize, the Yangtze River

[3] Delta urban and rural community development research papers in November 2015.

[4] < "The Belt and Road construction talent gap and countermeasure research", Tang Shiming, provincial key subject, in 2015 the city of the United Front Work Department knot. Results of <Talent Needs 
for Construction of English "One Belt One Road" > selected international conference keynote report.

[5] Research on the Construction of participating political parties serving Belt and Road, Tang Shiming, selected as the National, Provincial, and Municipal key speakers of the two sessions.

[6] "Belt and Road" the Cultural adaptation of overseas Chinese teenagers and their Dream of Root Soul. "the subject of the Chinese Federation of overseas Chinese 2015-2017." the achievement was selected as the representative speech of the Chinese Federation of overseas Chinese "kinship and affection of China. Chinese Bridge".

[7] Youth Accularization for Cognitive Therapy, Percutaneous CPCI SSH , Tang Shiming, et al ., 2016

< Youth Guidance for Happiness >, < CPCI-SSH >, Tang Shiming et al., 2016.

[8] Talent Talent Review for Construction of " One Belt One Road " , Tang Shiming , et al ., CPCI - SSH Pass2016

[9] "making good use of the outcome of the Hangzhou Summit to promote the internationalization of the city." et al., Tang Shiming and other important proposals for the 2017 sessions of Zhejiang and Hangzhou. 